\title{
Library Table Lighting
}

In an article in the June, 194I, issue of College and Research Libraries, Prof. Kraehenbuehl outlined basic principles of library lighting. The following article is a report on a series of experiments with fuorescent table lamps.

Illumination of the tables in the read1 ing and reference room is the most important lighting task in the library. At this position a worker may spend many hours using the eyes continuously at a very difficult and concentrated task of seeing. If the lighting is insufficient or the lighting quality is poor the expenditure of nervous energy may be such as to cause an excessive fatigue which if continued may lead to serious organic disturbances.

In a new building it is possible to install an adequate and satisfactory general lighting system, while in the older buildings this is frequently impossible. It may be that the wiring is inadequate or the structure of some of the older libraries is such that even with adequate wiring it would be impossible to do satisfactory remodelling of general lighting. In this event, second choice is a local lighting system in the form of table lamps. To do this with the incandescent lamp produces excessive heat close to the worker and it is difficult to reduce the brightness of the unit using these high brightness sources so that the reflected glare is not irritating.

Discussion will therefore center around the fluorescent type of table lamp because it is a line source of light of low bright- ness and high efficiency which is readily adaptable to table lamp service.

The problem may be divided into two parts, considering ( $\mathrm{I}$ ) the table itself and (2) the lighting equipment. The work surface and the conditions of lighting which surround the individual are as important as is the lighting of the book or the notes.

\section{The Table Surface}

The table may be either of a slopingtop or a flat-top type. General use of the flat-top table has led to the design of library table lamps with a light distribution for this type of table. Information from libraries where use has been made of the sloping-top table shows that the students as well as the library staff have found advantages which make this type of surface desirable.

At the beginning of the investigation of library table lamps, various types of tables with sloping-tops were studied. The width of the table should be forty-eight inches and from the reactions of a large number of students preference seems to be given to a table which has a pitch of one inch in seven. The section for the slopingtop on the forty-eight-inch table would consist of a six-inch flat portion in the center, elevated three inches above the edge of the table. In the remaining twenty-one inches on each side the slope will be three inches in twenty-one inches or one in seven inches. The one objection which may be raised is that pencils and 
pens roll from the surface. In the investigation it was found that the student quickly learned to place the pencil or pen in such a position that it did not roll.

The table with a sloping top did not increase the reflected glare nor did it introduce any marked difficulties into the problem of surface lighting. If this type of table becomes more generally used, the
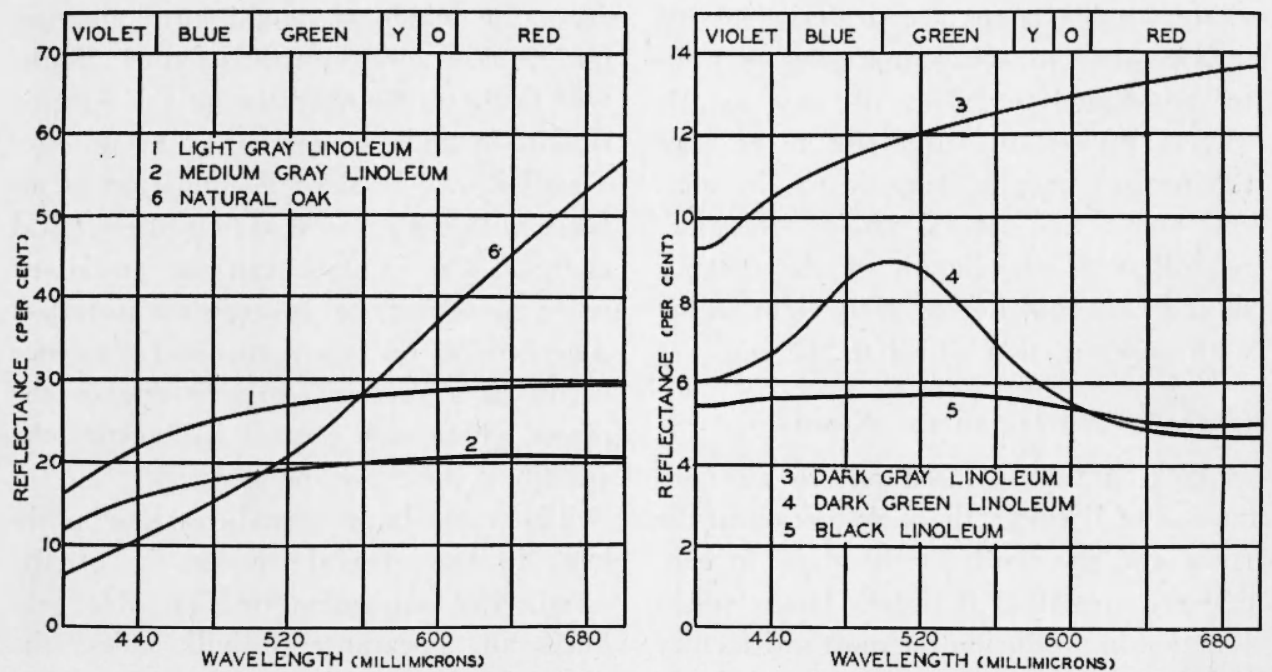

Figure i. Spectral Distribution Curves for Materials Used for
Library Table Tops.

design of the lamp should be such as to give a more uniform distribution than that given when using lamps designed for the flat-top table. With a demand for such a lamp it is certain that the manufacturers will produce one meeting the specific requirements introduced by a change in practice.

\section{Color of Table Surface Important}

The color of the table surface is also important. The finish, whether a natural wood or some form of composition material, should be light in color and free

from any gloss. The table surface should have a reflection factor of from 20 to 30 per cent or even higher depending upon the material and the problem of maintenance. Figure $I$ gives the spectral distribution of some of the materials offered on the market and those below 20 per cent reflection factor should not be considered seriously, if the object is to obtain

the most desirable surface upon which to work. The reflection of the various materials shown are:

\section{No.}

r. Light gray

2. Medium gray

3. Dark gray

4. Dark green

5. Black

6. Natural oak

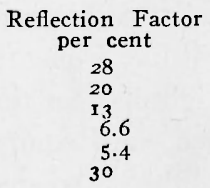

Number 6 is a natural oak finish in which the wood is filled, sanded, and covered with two coats of depolished varnish. This surface gives the highest reflection factor of those tested and is a surface which may be reproduced on many 
library tables now in service. The correct reflection factor may be obtained at no extra cost at the time a periodic renovation is being undertaken. The object in having the work surface light in color is to reduce the brightness contrast between the work surface and the light-colored book pages and paper in general use.

The question of the length of the table depends entirely upon local conditions. Library table lamps are so designed that it is possible to obtain multiples of units to accommodate tables of any length. Where fluorescent lamps are to be used the forty-eight-inch lamp, being the most efficient is the natural choice, therefore regardless of the length of the table it should be a multiple of forty-eight inches with an extra foot added to the ends.

\section{General Lighting in the Room}

As would be pointed out in any discussion of lighting, the illumination in the room and the finish of the room in general are important if library lamps are to function in producing the most satisfactory lighting conditions for prolonged tasks of reading, note taking, and writing.

The ceiling of the room should be light with a reflection factor of 75 per cent or more with a sidewall reflection factor of 50 to 60 per cent. The general illumination in the room should be such that the ratio of brightness of the surroundings will be from Io to 20 per cent of the brightness on the material which is being used. All equipment in the line of vision should be treated in a manner similar to the table top to lower the difference of brightness of objects which must be viewed continually or intermittently.

One of the most disturbing conditions may be caused by windows or other large areas of brightness. For a short period of time such an area may seem comfortable, but continued exposure will produce a direct glare which will become very irritating. These areas should be properly shaded or the tables should be so placed as to remove them from the line of vision.

In good practice, in rooms where the natural illumination comes from one side of the room, the lamps located farthest from the windows should burn continuously. The correct installation of circuits will facilitate the operation of the lighting system in such a manner as to produce a satisfactory level of illumination at all times with the greatest saving of electrical energy. The control can be automatic when photoelectrical controls are installed. The general reading rooms and reference rooms of a library represent one of the places where such control will justify the additional first cost.

The table lamp introduces new problems in the general appearance of the room. The equipment on the table produces an appearance of bulk unless the dimensions are limited and where there is a problem of discipline in the school library the lamps themselves offer a screen which will hide the workers from the supervision of the attendant.

\section{Fluorescent Library Table Lamp}

Compactness and efficiency of the fluorescent lamp make it the logical type of source for the library service. It is not free from undesirable features but for the specific task considered, it represents as close to perfection as may be attained today.

One of the usual objections to the fluorescent installation is a hum which can only be diminished and not completely removed. First it is essential that 
the auxiliary equipment be of the highest quality. At this point it is foolish to consider price rather than quality in purchasing. These units have the hum reduced to a minimum. The unit is usually mounted in the lamp equipment proper and if this is heavily constructed and the ballasts properly cushioned the hum will be of very low level. Some experimental work has shown that the surest way to reduce the hum to a minimum and to be assured that it will not increase with the age of the equipment is to mount the ballast on cushioning under the table proper where the mass of the support is large and the period of normal vibration will not fall within the range of the hum, thereby eliminating the possibility of resonance. This increases to some extent the wiring needed, but it places the ballast where it is easily accessible as well as making available an excellent surface on which the ballast may be properly and firmly cushioned.

\section{Individual Controls}

For economical operation it is desirable to have individual controls at the lamps so that when the work surface is not in use the lamp can be turned off by the individual in charge. The length of the unit will determine the number of local switches needed; one for each fourfoot length of table seems satisfactory.

The mechanical construction of the lamp should be according to superior specifications, for a lightweight metal produces an inferior product and reflection surfaces depend upon the material for their efficiency. For light control either specular surfaces or lenses must be used. It is necessary to properly maintain the lamps, therefore all the parts which must be replaced must be readily accessible.

\section{Reflected Glare}

To reduce the reflected glare from the work it is necessary to have some form of diffusing material below the lamps located in the equipment. It has been found that a sanded glass with a transmission of 70 per cent will reduce the brightness of the lamp sufficiently and at the same time will not lower the efficiency of the equipment seriously. Foot-candles alone should not be taken as an indication of the efficiency of the source for the quality of light obtained is equally important.

When glass covers are used, it is best to so design the lamp that the glass may be slipped into the fixture from the end, and for servicing of lamps and switches the glasses may be slipped over each other in the equipment proper. This glass covering also eliminates the possibility of tampering with the lamps and switches in the equipment.

At this point it is necessary to call attention to the fact that table lamps of the types discussed in the last part of the paper are for reading with the book or paper on the surface of the table, the normal condition in the school and reference library. Where the lamps are to be used for reading with the book or paper on the edge of the table and tilted at a sharp angle, the line of lamps should be doubled with a single line of sources about one foot from the edge of the table. This arrangement is not good for general school use, but would prove more satisfactory in the public library where there is a tendency to read and not to work on assignments and make notes. The equipment offered for sale today is for a surface used for work, not for a surface used for leisure reading. To tilt the book or paper severely makes use of the general lighting 

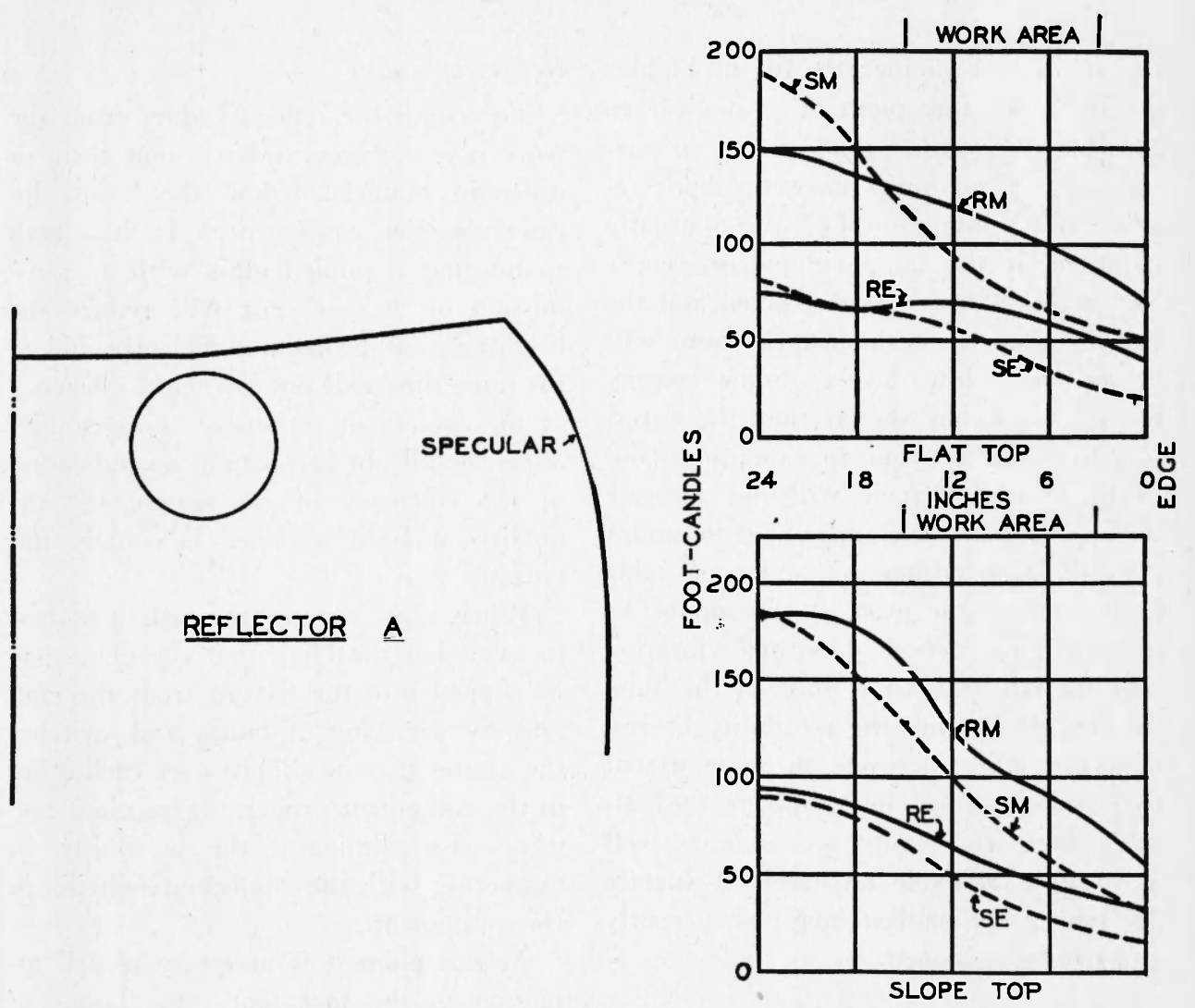

figure 2. Reflector Shape A and Foot-Candle Distribution Curves from Center of Lamp to Edge of Table. (RM reflector only at middle of lamp, RE reflector only at end of lamp, SM at middle of lamp with sanded glass cover, $\mathrm{SE}$ at end of lamp with sanded glass cover. See Table A).

\section{EQUIPMENT A}

\section{Reflector \\ Only}

Type Table

Mounting

Transmission Factor (per cent)

Reflected Brightness

(candle/sq. in.)

Table Average

(foot-candles)

Work Area Average

(foot-candles)

Efficiency (per cent)

Table Top

Efficiency (per cent)

Work Area
Sloping Flat

I $5 \frac{1}{2}$ " I $8 \frac{1}{2}$ " I $5 \frac{1}{2}$ "

$\begin{array}{lll}0.35 & 0.24 & 0.32\end{array}$

9I $90 \quad 100$

$\begin{array}{lll}82 & 89 & 93\end{array}$

$\begin{array}{lll}50.5 & 50.0 \quad 55.5\end{array}$

$22.8 \quad 24.7 \quad 25.8$

See Fig. 2

Heavy Sanded

Sanded

Sloping Flat I $5 \frac{1}{2}$ " I $8 \frac{1}{2} "$

$79.0 \quad 79.0$

$0.23 \quad 0.22$

$\begin{array}{ll}78 & 82\end{array}$

$73 \quad 66$

$43.3 \quad 45.5$

$20.3 \quad 18.3$

8.3 

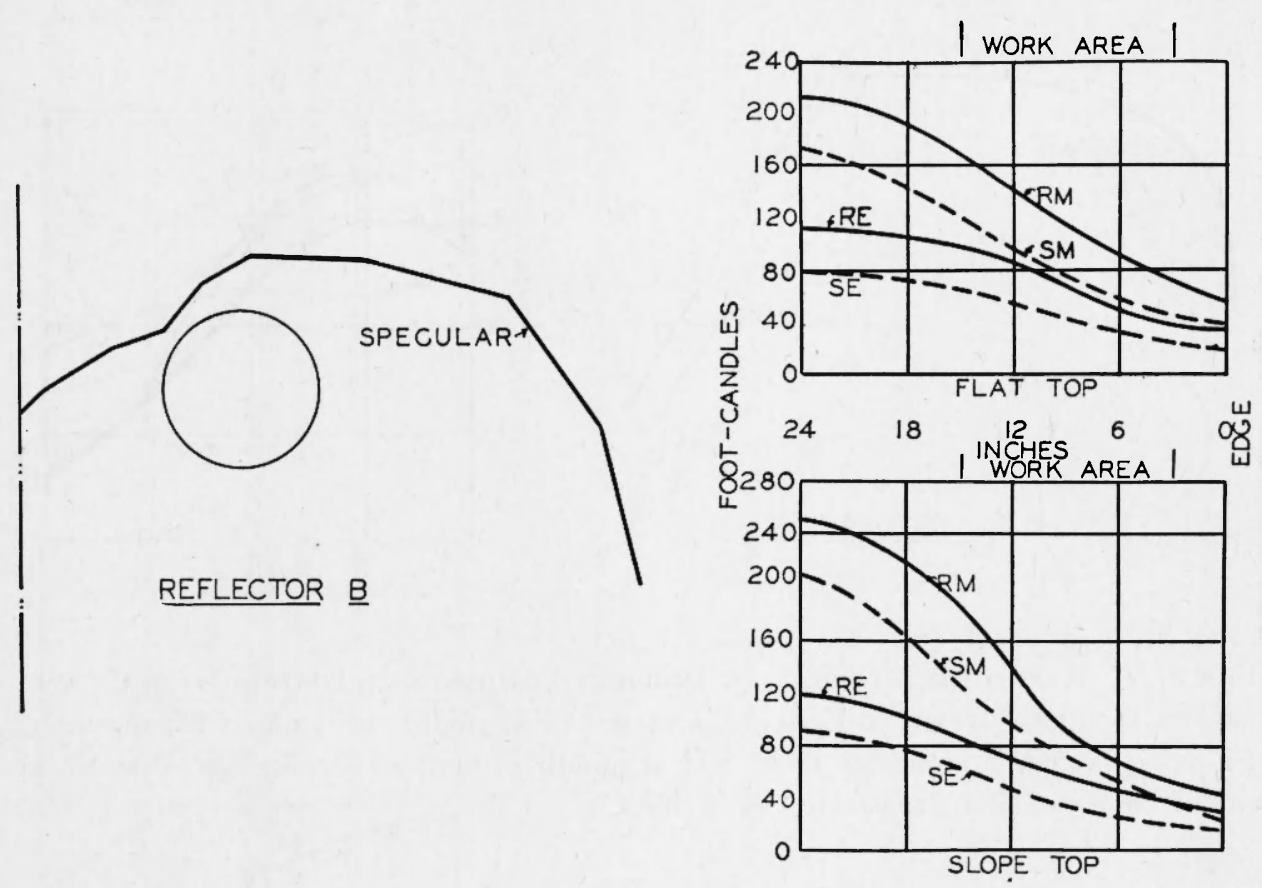

figure 3. Reflector Shape B and Foot-Candle Distribution Curves from Center of Lamp to Edge of Table. (RM reflector only at middle of lamp, RE reflector only at end of lamp, SM at middle of lamp with sanded glass cover, SE at end of lamp with sanded glass cover. See Table B).

\section{EQUiPMENT B}

Type Table

Mounting

Transmission Factor (per cent)

Reflected Brightness (candle/sq. in.)

Table Average (foot-candles)

Work Area Average (foot-candles)

Efficiency (per cent) Table Top

Efficiency (per cent) Work Area

\section{Reflector \\ Only}

Sloping Flat

I $5 \frac{1}{2}$ " I $8 \frac{1}{2} "$

$0.24 \quad 0.21$

IO7 II I

$82 \quad 96$

$59.5 \quad 61.6$

$22.8 \quad 26.7$
Light

Sanded

Sloping Flat

$15^{\frac{1}{2}}$ 1" $18 \frac{11}{2}$

$79 \quad 79$

0.190 .19

$79 \quad 79$

$56 \quad 63$

$43.9 \quad 43.9$

I $5.5 \quad$ I 7.5

See Fig. 3

without gaining the advantages of the library table lamp.

Figures 2 through 8 and tables from $A$ to $G$ give the specific information concerning various types of library table lamps. The tables list the quantitative values while the figures give the shapes of the reflectors and the distribution of the illumination on the surface of both flatand sloping-top tables. 

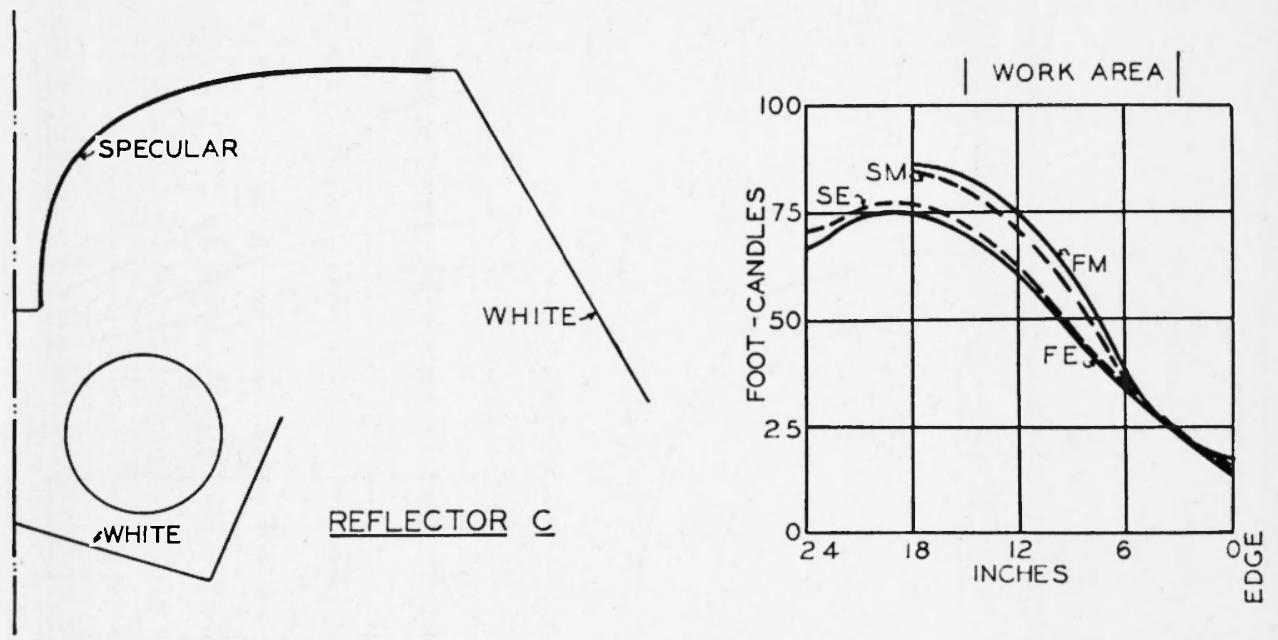

Figure 4. Reflector Shape C, an Indirect Equipment. Distribution Curves from Center of Lamp to Edge of Table. (FM middle of lamp on flat-top table, $\mathrm{FE}$ at end of lamp on flat-top table, SM at middle of lamp on sloping-top table, SE at end of lamp on sloping-top table. See Table C)

Type Table
Mounting
Reflected Brightness (candle/sq. in.)
Table Average (foot-candles)
Work Area Average (foot-candles)
Efficiency (per cent) Table Top
Efficiency (per cent) Work Area

\section{Equipment C}

Sloping

$13^{\prime \prime}$

0.18

34

34

18.9

9.4
Flat

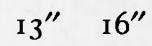

$0.13 \quad 0.14$

$36 \quad 33$

$35 \quad 37$

$20.0 \quad 18.3$

$9.7 \quad 10.3$

See Fig. 4

\section{Comparing Performance}

Since there have never been specifications established for the testing of this type of lamp it is necessary to establish some method for comparing the performance of the equipment. Measurements of illumination were made with a brightness meter and a magnesium oxide disc; the brightness measurements were made with the same brightness meter. Observations were taken on the surface of the table at six-inch intervals. Averages were computed for two conditions:
I. The table average represents the average illumination over the surface of a forty-eight-inch table to a line twelve inches beyond the end of the fluorescent lamps.

2. The work area average represents more accurately the effective illumination of the lamp, for it represents the area actually used by the student. This area is a strip twelve inches wide measured three inches from the front edge of the table to a line fifteen inches from the front edge of the table, at the ends to 

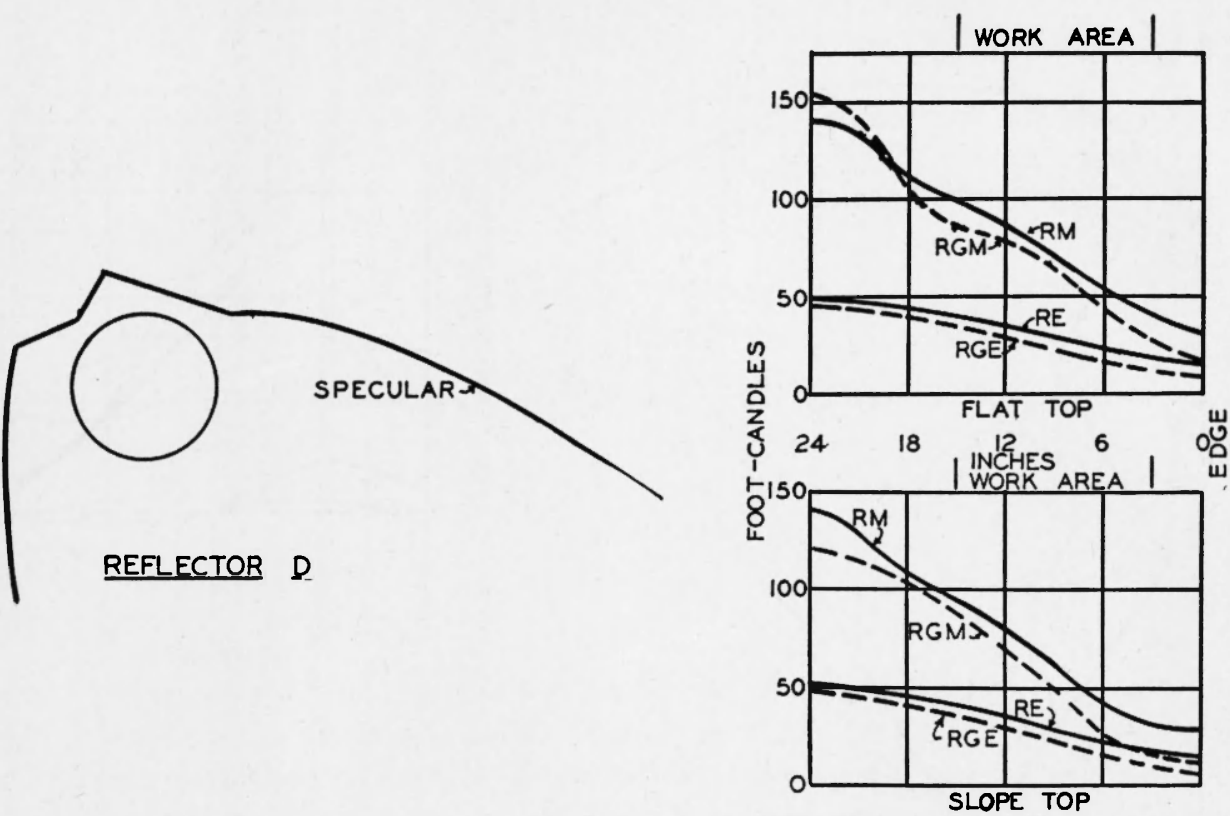

Figure 5. Reflector Shape D and Foot-Candle Distribution Curves from the Center of Lamp to Edge of Table. (RM reflector only at middle of lamp, $\mathrm{RE}$ reflector only at end of lamp, RGM at middle of lamp with ribbed glass cover, RGE at end of lamp with ribbed glass cover. See Table D)

\section{EQUIPMENT D}

Reflector 50 per cent Clear 50 per cent Ribbed 70 per cent Pebbled Only 50 per cent Sanded 50 per cent Sanded 30 per cent Sanded Type Table Sloping Flat Sloping Flat Sloping Flat Sloping Flat

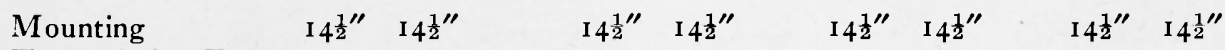
Transmission Factor (per cent)

(a) Sanded

(b) Other Surface

Reflected Brightness
(candles/sq. in.)
0.13
0.14

(a) Sanded

(b) Other Surface
$0.14 \quad 0.12$
$0.120 .1 \mathrm{I}$

$0.075 \quad .065$

$89.2 \quad 89.2$

Table Average

(foot-candles)

Work Area Average

(foot-candles)

$48 \quad 52$

$0.08 \quad .075$

$0.095 \quad 0.12$

$0.09 \quad 0.13$

Efficiency (per cent)

Table Top

$\begin{array}{ll}38 & 47\end{array}$

$4^{2} \quad 4^{2}$

4I 44

$43 \quad 4 \mathrm{I}$

$31 \quad 32$

$30 \quad 35$

$33 \quad 29$

Efficiency (per cent)

Work Area

$26.6 \quad 28.9$

$23 \cdot 3 \quad 23 \cdot 3$

$22.8 \quad 24 \cdot 4$

$23.9 \quad 22.8$

$8.6 \quad 8.9$

$8.3 \quad 9.7$

$9.2 \quad 8.1$

See Fig. 5 

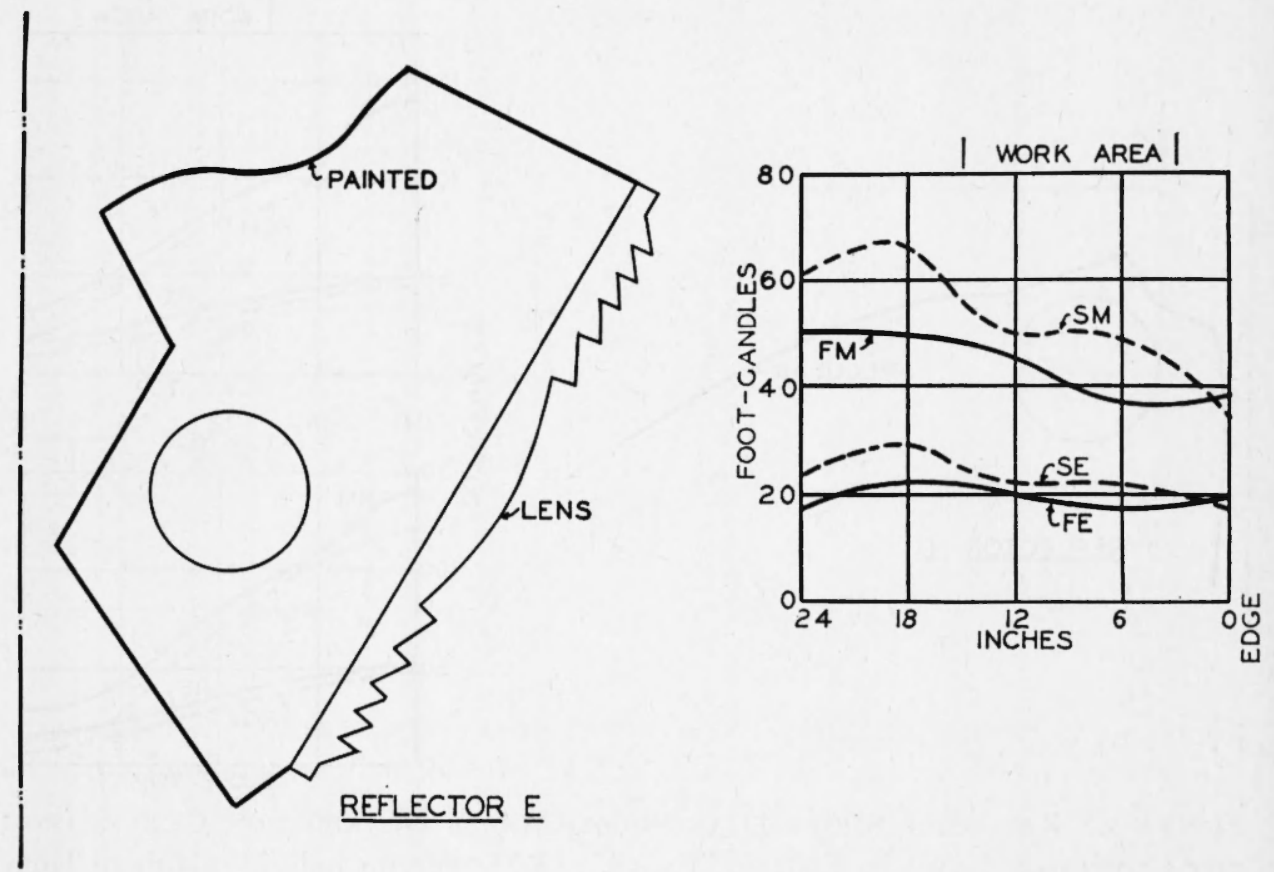

Figure 6. Reflector Shape E, a Lens Controlled lighting Equipment. Distribution Curves from the Center of Lamp to Edge of Table. (FM at middle of lamp on a flat-top table, FE at end of lamp on a flat-top table, SM at middle of lamp on a sloping-top table, $\mathrm{SE}$ at end of lamp on a sloping-top table. See Table E).

\section{EQUipMent E}

Type of Table

Mounting

Reflected Brightness (candles/sq. in.)

Table Average (foot-candles)

Work Area Average (foot-candles)

Efficiency (per cent) Table Top

Efficiency (per cent) Work Area

$\begin{array}{ll}\text { Sloping } & \text { Flat } \\ 15^{\frac{1}{2}} & 20^{\prime \prime} \\ .055 & .055 \\ 32 & 27 \\ 29 & 25 \\ 17.8 & 15.0 \\ 8.1 & 6.9\end{array}$

See Fig. 6

a line twelve inches beyond the end of the fluorescent lamp.

The efficiency of the lamp for the two areas is computed on the lumen output of a daylight fluorescent lamp. The ratio of the total lumens on the area to the lumens generated by the lamps has been defined as the efficiency of performance of the library lamp. Daylight fluorescent lamps were used in the test.

The lamps were operated one hundred hours before the tests were made. The daylight lamp represents the low values of foot-candles and was used because of a tendency to specify this color temperature. Except where it is desired to color match 

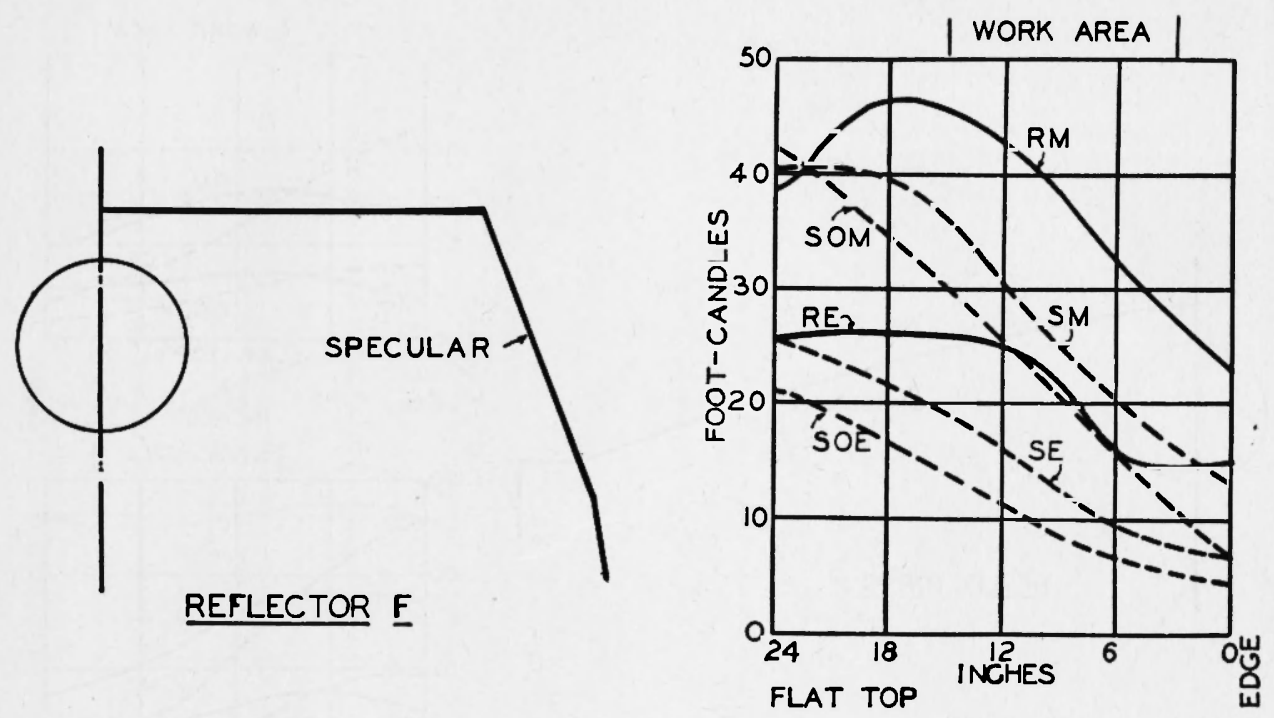

Figure 7. Reflector Shape and Foot-Candle Distribution Curves from Center of Lamp to Edge of Table. (RM reflector only at middle of lamp, RE reflector only at end of lamp, SM at middle of lamp with sanded glass cover, SE at end of lamp with sanded glass cover, SOM at middle of lamp with sanded flashed opal glass cover, SOE at end of lamp with sanded flashed opal glass cover. See Table F)

Type of Table

\section{EQUipMent F}

Mounting

Transmission Factor (per cent)

Reflected Brightness (candles/sq. in.)

Table Average (foot-candles)

Work Area Average (foot-candles)

Efficiency (per cent) Table Top

Efficiency (per cent) Work Area

Flat

\section{$18 \frac{1}{2} "$}

27.1

0.041

20

15

22.2

8.3

See Fig. 7

natural light entering the windows it is more economical to use the white light which supplies approximately 23 per cent more lumens for the same wattage. All research indicates that there is no benefit to seeing by using the daylight lamps.

The equipments $\mathrm{A}, \mathrm{B}, \mathrm{C}, \mathrm{D}$, and $\mathrm{E}$ are two-lamp equipment while $F$ and $G$ are single-lamp types. The first are the most expensive both as to first cost and operation while the last two have a lower first cost and operating cost. Where the lamps are contained in a common reflector there is some reduction in the stroboscopic effect, but the light mixture from the two-lamp combination is not enough to give the same effect as obtained with ceiling equipment. The single-lamp types are distinctly stroboscopic, but in an installation of this type which was under observation there were no complaints on this score. 

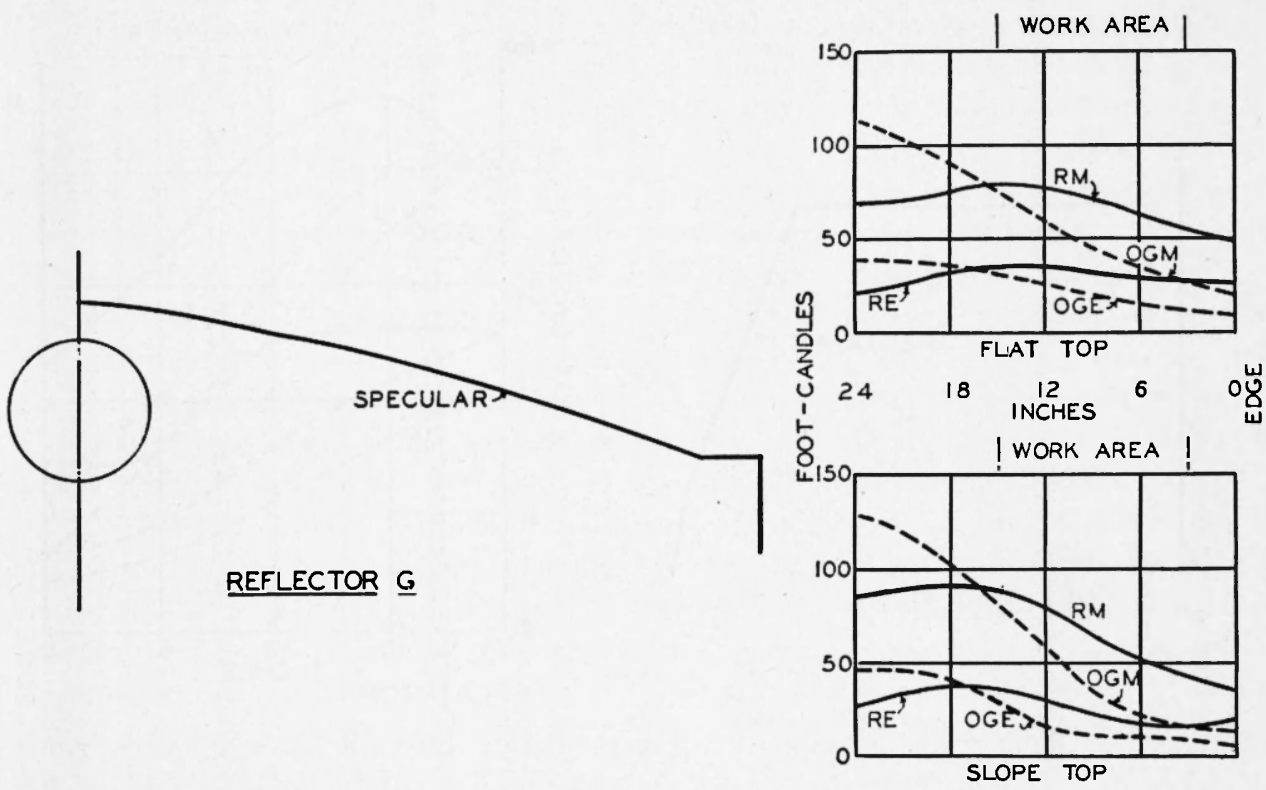

Figure 8. Reflector Shape $G$ and Foot-Candle Distribution Curves from Center of Lamp to Edge of Table. (RM reflector only at middle of lamp, RE reflector only at end of lamp, OGM at middle of lamp with flashed opal glass cover, OGE at end of lamp with flashed opal glass cover. See Table G)

Type Table

Mounting from Low Point Table

Trans. (per cent)

Reflected Brightness

Table Average

Work Average

Table Top Efficiency (per cent)

Work Area Efficiency (per cent)

\section{EquipMENT G}

\section{Reflector}

Only

Sloping Flat

I6" 16 "

$\begin{array}{ll}1.52 & 1.78\end{array}$

$36 \quad 40$

$37 \quad 42$

$32.4 \quad 37$

$20.6 \quad 23.3$

See Fig. 8

\section{岁}


given it would be necessary to increase the general room illumination found in many libraries considerably to attain the proper surrounding illumination.

The material in the tables and figures has been arranged to give information concerning typical lamps being offered for the service being discussed. It has been arranged and analyzed for the consideration of those who are studying the use of fluorescent lamps for library tables. The curves on the figures show the illumination distribution at the center of the forty-eight-inch lamp and at the end of the lamp with reflector only and with diffusing material over the bottom. The analysis, in those instances where it is possible, considers both the flat-top and the sloping-top table. The reader can draw his own conclusions concerning the merits of the various lamps. It is necessary to reduce the direct and reflected brightness to as low a value as possible. Where no record is made of direct glare, it will be understood that no part of the reflector or lamp was in the line of vision. The reflected glare represents the brightest portion of a glazed piece of paper ( 83 per cent reflection) in the normal study position.

\section{Summary}

A study of the requirements of the library table lamp shows that a single row of fluorescent lamps in a suitable equipment properly designed is capable of supplying the necessary illumination for the work area. The lamp should be mounted with the lowest portion of the reflector sixteen inches above the lowest edge of the table whether the table has a flat or a sloping top. For the sloping top this is thirteen inches above the sixinch center strip.

To reduce the reflected glare the equipment should have some form of diffusing media below the fluorescent lamp and this can be of relatively high transmission.

The surroundings should be illuminated and treated according to the recommendations for any general lighting system. The work area and the equipment should be of a lighter color than is the general practice in the library at present. The equipment should be of good material and the workmanship produce a sturdy and durable table lamp. Provisions for servicing should be a part of the specification.

It would be desirable to have a qualified committee to study the problem of equipment and specifications for library table lamps establishing some standard requirements similar to those that have governed the I.E.S. specified lamp. The one factor which is hindering the adoption of some type of lamp of this sort is the confusion concerning the merits of the equipment being offered for sale.

The lack of a reliable, approved equipment or a clear-cut specification which may be subjected to standard tests, is retarding the installation of many local lighting systems in libraries and thereby many are suffering from a lack of adequate lighting, not because the library administration is not conscious of the need for this lighting, but because the administration is confused by the many claims and counterclaims made by sales organizations and has no information sponsored by a disinterested agency concerning the merits and requirements for a good lamp. 